\title{
THE CORRELATION BETWEEN DENTAL CARIES AND ORAL HEALTH RELATED QUALITY OF LIFE AMONG VISUALLY IMPAIRED CHILDREN
}

\author{
Fitri Diah Oktadewi*, Indah Titien Soeprihati**, Lisdrianto Hanindriyo ***
}

'Prodi S2 IImu Kedokteran Gigi Fakultas Kedokteran Gigi Universitas Gadjah Mada

* Departemen IImu Kedokteran Gigi Anak Fakultas Kedokteran Gigi Universitas Gadjah Mada

"* Departemen IImu Kedokteran Gigi Pencegahan dan IImu Kesehatan Gigi Masyarakat Fakultas Kedokteran Gigi Universitas Gadjah Mada

Correspondence : Fitri Diah Oktadewi, Prodi S2 IImu Kedokteran Gigi Fakultas Kedokteran Gigi Universitas Gadjah Mada Email : fitridiahoktadewi@gmail.com

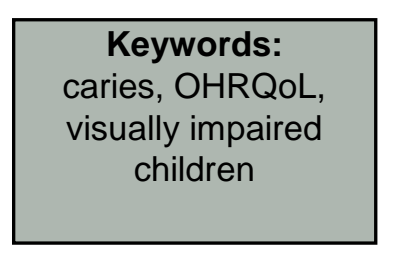

\begin{abstract}
Background: Visually impaired children have a low vision to visualize the process of plaque removal on teeth resulting in dental caries progression. Dental caries has an impact on children's quality of life. The impact of dental caries on oral health related quality of life among visually impaired children remains mostly unknown. This study aimed to determine the correlation between dental caries and oral health related quality of life (OHRQoL) among visually impaired children.

Method: This study was an observational study with a cross sectional design and conducted across four regencies in Yogyakarta and Central Java Province. A total of 70 visually impaired children aged 7-18 participated in this study. The participants underwent a dental examination to determine their caries experience using DMFT/dmft index. Oral health related quality of life was measured using the COHIP SF 19 questionnaire with interviewing method.

Result: Data analysis showed that caries frequency was $94,3 \%$. The mean number of DMFT/dmft index was $4,8 \pm 2,743$. Spearman correlation test showed the $p$ value was $0,611(p>0,05)$ for the correlation between DMFT/dmft index and OHRQoL.

Conclusion: This study showed no correlation between dental caries and oral health related quality of life among visually impaired children.
\end{abstract}

\section{PENDAHULUAN}

Kesehatan rongga mulut merupakan aspek penting dalam kesehatan umum pada anakanak tak terkecuali pada anak berkebutuhan khusus ${ }^{1}$ Anak tunanetra merupakan bagian dari anak berkebutuhan khusus yang memerlukan perhatian khusus dalam kesehatan gigi dan mulut. Tunanetra dibagi menjadi dua yakni buta total (blindness) dan low vision atau kondisi penglihatan terbatas. Pada tahun 2010 terdapat 18,9 juta anak tunanetra berusia 0-14 tahun dengan pembagian 17,5 juta mengalami low vison dan 1,4 juta mengalami kebutaan total yang tersebar di enam wilayah besar di dunia menurut survey $\mathrm{WHO}^{2}$. Kesehatan rongga mulut pada anak tunanetra lebih rendah dibandingkan anak berpenglihatan normal. Penelitian menunjukkan bahwa kebersihan rongga mulut anak tunanetra cenderung buruk disertai prevalensi karies yang cukup tinggi ${ }^{3,4}$. Shewale dkk. ${ }^{5}$ menyebutkan bahwa anak tunanetra tidak mampu memvisualisasikan kondisi plak pada permukaan gigi sehingga mengakibatkan lemahnya proses perawatan kebersihan rongga mulut yang berujung pada peningkatan karies. Berbagai masalah dalam rongga mulut yang diderita anak tunanetra seperti 
kebersihan rongga mulut yang kurang dan karies yang tidak ditangani berkaitan langsung dengan ketidaknyamanan, nyeri gigi, hingga mempengaruhi kualitas hidup terkait kesehatan rongga mulut anak tersebut dan juga orang tua atau keluarga ${ }^{6,7}$. Kualitas hidup terkait kesehatan rongga mulut adalah respon dari masing-masing individu dalam kehidupannya sehari-hari terhadap fungsi fisik, psikis dan sosial sebagai akibat dari status kesehatan gigi yang dimilikinya ${ }^{8}$. Indikator kualitas hidup memberikan informasi detail tentang konsekuensi dari tunanetra serta peluang intervensi, serta menghasilkan data yang lebih komprehensif untuk dipahami stakeholder dalam meningkatkan komunikasi dan pengambilan keputusan ${ }^{9}$.

Penelitian mengenai kualitas hidup terkait kesehatan rongga mulut pada anak-anak normal telah berkembang namun sebaliknya penelitian sejenis pada anak berkebutuhan khusus seperti anak tunanetra masih amat terbatas. Penelitian Tagelsir dkk. ${ }^{10}$ dan Singh dkk. ${ }^{11}$ pada anak tunanetra menggunakan alat ukur kuesioner ChildOral Impact on Daily Performance (C-OIDP) menunjukkan hasil yang berbeda. Tagelsir dkk. ${ }^{10}$ menyebutkan bahwa kualitas hidup terkait kesehatan rongga mulut anak tunanetra tidak memiliki hubungan signifikan terhadap pengalaman karies sedangkan Singh dkk.11 membuktikan bahwa terdapat hubungan signifikan antara pengalaman karies terhadap kualitas hidup terkait kesehatan rongga mulut pada anak tunanetra. Kontradiksi hasil kedua penelitian tersebut tentunya membutuhkan kajian penelitian lebih lanjut. Berbagai alat ukur kualitas hidup terkait kesehatan rongga mulut pada anak telah dikembangkan dan tervalidasi. Penelitian ini akan menggunakan alat ukur Child Oral Health Impact Profile (COHIP). COHIP adalah salah satu alat ukur kualitas hidup terkait kesehatan rongga mulut yang dikembangkan pada anak usia 7-18 tahun dengan berbagai kondisi oral, kelainan sistemik hingga etnik. COHIP merupakan instrumen pertama yang menggabungkan dampak positif dan negatif kesehatan dalam kualitas hidup terkait kesehatan rongga mulut ${ }^{12-14}$.

Tujuan penelitian ini adalah untuk mengetahui hubungan antara karies gigi dengan kualitas hidup terkait kesehatan rongga mulut pada anak tunanetra. Penelitian ini dilakukan pada anak tunanetra di empat kabupaten di Provinsi D.I Yogyakarta dan Jawa Tengah. Kedua provinsi tersebut berada pada enam besar provinsi dengan jumlah sekolah luar biasa dan siswa berkebutuhan khusus terbanyak di Indonesia.

\section{METODE PENELITIAN}

Jenis penelitian ini adalah analitik observasional dengan rancangan studi cross sectional. Penelitian ini dilaksanakan pada bulan Februari-Maret 2020 setelah mendapatkan surat keterangan kelaikan etik dari Komisi Etik Penelitian Fakultas Kedokteran Gigi Universitas Gadjah Mada no.00351/KKEP/FKG-UGM/EC/2020. Perhitungan besar minimal sampel penelitian korelasional mempertimbangkan koefisien korelasi antarvariabel dari penelitian terdahulu ${ }^{11}$ sehingga diperoleh besar sampel minimal 70 orang. Sebanyak 70 anak tunanetra di Kabupaten Sleman, Bantul, Kota Yogya dan Kabupaten Klaten terlibat dalam penelitian ini yang dipilih melalui metode purposive sampling. Teknik ini dilakukan dengan cara mengambil subjek berdasarkan tujuan dan pertimbangan tertentu dari peneliti 
misalnya alasan keterbatasan waktu, tenaga dan dana. Adapun kriteria inklusi responden adalah 1) anak tunanetra dengan kategori buta total dan low vision, 2) berusia 7-18 tahun dan 3) mendapatkan persetujuan orang tua dan bersedia terlibat dalam penelitian. Anak tunanetra yang mengalami retardasi mental atau jenis ketunaan lain (tunaganda) atau non-kooperatif tidak dilibatkan dalam penelitian ini.

Pemeriksaan rongga mulut dilakukan oleh satu orang pemeriksa. Karies gigi diukur menggunakan indeks DMFT/dmft menurut WHO 15 dengan kriteria 1) $\mathrm{D} / \mathrm{d}=$ decayed atau gigi yang berlubang karena karies gigi atau restorasi yang telah rusak akibat karies, 2) $\mathrm{M} / \mathrm{m}=$ missing atau gigi yang dicabut karena karies gigi, dan 3) F/f =filling atau gigi yang ditambal atau ditumpat karena karies dan dalam keadaan baik. Perhitungan DMFT /dmft untuk individu diperoleh dengan menjumlahkan tiap komponen $\mathrm{D}, \mathrm{M}$ dan $\mathrm{F}$ serta d, m, f untuk gigi desidui. Liu dkk. ${ }^{16}$ menambahkan bahwa skor karies untuk gigi bercampur dapat diperoleh dengan menjumlahkan skor dt+DT, mt+MT dan ft+FT tiap individu.

Kualitas hidup terkait kesehatan rongga mulut diukur menggunakan kuesioner Child Oral Health Impact Profile-Short Form 19 (COHIP-SF 19) versi Indonesia ${ }^{17}$. Kuesioner ini terdiri dari 19 aitem pertanyaan yang terbagi dalam tiga domain yakni: kesehatan rongga mulut (oral health) sebanyak 5 aitem pertanyaan, kesejahteraan fungsional (functional wellbeing) sebanyak 4 aitem pertanyaan dan kesejahteraan sosio-emosional (socio-emotional wellbeing) sebanyak 10 aitem pertanyaan. Proses pengisian kuesioner dilakukan melalui proses wawancara oleh satu orang pemeriksa. Setiap pertanyaan akan direspon melalui lima poin skala Likert sebagai berikut: tidak pernah (nilai 5), sangat jarang (nilai 4), kadangkadang (nilai 3), lumayan sering (nilai 2), hampir setiap saat (nilai 1). Namun, terdapat dua pertanyaan yang bernada positif (favorable) akan diberi penilaian sebagai berikut: tidak pernah (nilai 1), sangat jarang (nilai 2), kadang-kadang (nilai 3), lumayan sering (nilai 4), hampir setiap saat (nilai 5). Nilai kualitas hidup akan dijumlahkan dari jawaban setiap pertanyaan dengan rentang nilai 19-95. Uji reliabilitas dan validitas kuesioner COHIP-SF 19 versi Indonesia dilakukan pada 30 responden. Selanjutnya, 30 responden tersebut akan dilibatkan kembali sebagai responden penelitian. Analisis menggunakan program IBM SPSS Statistic Version 25 diperoleh nilai alpha cronbach sebesar 0,751 dengan 6 pertanyaan tidak valid yakni pertanyaan nomor 3, 8. 9, 11, 16 dan 19. Enam pertanyaan di-drop out sehingga diperoleh 13 pertanyaan valid dengan nilai alpha cronbach 0,803. Uji Spearman dilakukan untuk mengetahui hubungan antara karies gigi dan kualitas hidup terkait kesehatan rongga mulut pada anak tunanetra.

\section{HASIL PENELITIAN}

Pemeriksaan rongga mulut pada 70 responden siswa tunanetra berusia 7-18 tahun (dengan nilai rerata $13,84 \pm 3,291$ ) menunjukkan prevalensi karies sebesar 94,3\% (dengan nilai rerata skor DMFT/dmft 4,8 $\pm 2,743$ ). Distribusi frekuensi responden secara lengkap termuat pada Tabel 1. Penilaian kualitas hidup terkait kesehatan rongga mulut (OHRQoL) pada responden siswa tunanetra melalui metode wawancara menghasilkan respon yang didominasi dengan jawaban "tidak pernah". Distribusi frekuensi 
jawaban menggunakan kuesioner COHIP SF-19 versi Indonesia termuat dalam tabel 2.

Tabel 1. Distribusi frekuensi responden

\begin{tabular}{clcc}
\hline No. & $\begin{array}{c}\text { Karakteristik } \\
\text { Responden }\end{array}$ & N & (\%) \\
\hline 1. & Usia responden & & \\
\hline & $7-12$ tahun & 26 & 37,1 \\
& 13-18 tahun & 44 & 62,9 \\
\hline 2. & Jenis kelamin & & \\
\hline & Laki-laki & 39 & 55,7 \\
& Perempuan & 31 & 44,3 \\
\hline 3. & Jenis kebutaan & & \\
\hline & Buta total & 34 & 48,6 \\
& Low Vision & 36 & 51,4 \\
\hline 4. & Pengalaman & & \\
& karies & & \\
\hline & Ya & 66 & 94,3 \\
& Tidak & 4 & 5,7 \\
\hline & Total & $\mathbf{7 0}$ & $\mathbf{1 0 0}$ \\
\hline
\end{tabular}

Keterangan : $\mathbf{n}$ jumlah responden; \% persentase

Uji asumsi klasik dilakukan sebagai prasyarat sebelum dilakukan analisis bivariat. Uji normalitas menggunakan Kolmogorov Smirnov menunjukkan data skor DMFT/dmft berdistribusi normal sedangkan skor OHRQoL berdistribusi tidak normal $(p=0,083$ dan $p<0,001)$. Analisis korelasi menggunakan uji Spearman dilakukan untuk mengetahui hubungan antara skor DMFT/dmft terhadap skor OHRQoL untuk tiap domain dan skor total dengan hasil tidak signifikan seperti tercantum pada Tabel 3.

\section{DISKUSI}

Penelitian ini menunjukkan bahwa prevalensi karies pada 70 responden anak tunanetra berusia 7-18 tahun sebesar 94,3\% dengan nilai rerata skor DMFT/dmft 4,8 $\pm 2,743$. $\mathrm{Hal}$ ini senada dengan penelitian terdahulu yang menyebutkan bahwa anak tunanetra memiliki kecenderungan karies tinggi dan kebersihan rongga mulut yang buruk ${ }^{3,4}$. Ketidakmampuan anak tunanetra dalam memvisualisasikan plak pada permukaan gigi sebagai penyebab karies yang progresif. Karies tersebut dipicu oleh praktek menjaga kebersihan gigi dan mulut yang kurang, Sebanyak $77 \%$ anak tunanetra menyikat gigi tanpa adanya pendampingan dan 60,5\% tidak pernah melakukan kunjungan ke dokter gigi 1. Pengawasan dan pendampingan orang tua, keluarga atau pengasuh akan meningkatkan kontrol pemeliharaan kesehatan gigi dan mulut anak tunanetra sehingga mereka mampu mandiri tanpa bantuan ${ }^{18,19}$ meskipun memiliki kelemahan koordinasi manual-visual dalam menyikat gigi 20 . Penelitian menunjukkan bahwa status kebersihan gigi dan mulut anak tunanetra menjadi lebih baik bila orang tua dan pengasuh mendampingi dan memperhatikan pemeliharaan kebersihan gigi anaknya ${ }^{21}$.

Karies dapat mempengaruhi kualitas hidup anak-anak. Penilaian kualitas hidup terkait kesehatan rongga mulut pada penelitian ini menggunakan kuesioner COHIP SF-19. COHIP merupakan instrumen pertama yang menggabungkan dampak positif dan negatif kesehatan dalam kualitas hidup terkait kesehatan rongga mulut ${ }^{12-14}$.

Penelitian ini menunjukkan tidak terdapat hubungan karies dengan kualitas hidup terkait kesehatan rongga mulut, baik dari aspek oral health, kesejahteraan fungsional (functional wellbeing) dan kesejahteran sosio-emosional (socio-emotional wellbeing). Artinya, meskipun rerata karies cukup tinggi namun secara keseluruhan tidak mempengaruhi kualitas hidup terkait kesehatan rongga mulut anak tunanetra. 
Tabel 2. Distribusi frekuensi respon terhadap kuesioner COHIP SF 19

\begin{tabular}{|c|c|c|c|c|c|}
\hline Pertanyaan & TP & SJ & $\begin{array}{c}\text { Jawaban } \\
\text { n (\%) } \\
\text { KK }\end{array}$ & LS & HSS \\
\hline \multicolumn{6}{|l|}{ Kesehatan Rongga Mulut (Oral Health) } \\
\hline Sakit gigi & $51(72,9)$ & $12(17,1)$ & $7(10)$ & $0(0)$ & $0(0)$ \\
\hline $\begin{array}{l}\text { Merasa gigimu tidak rapih atau ada celah } \\
\text { di antara gigi }\end{array}$ & $26(37,1)$ & $11(15,7)$ & $13(18,6)$ & $13(18,6)$ & $7(10)$ \\
\hline Merasa mulutmu bau & $28(40)$ & $13(18,6)$ & $18(25,7)$ & $11(15,7)$ & $0(0)$ \\
\hline Berdarah gusinya & $49(70)$ & $13(18,6)$ & $5(7,1)$ & $3(4,3)$ & $0(0)$ \\
\hline \multicolumn{6}{|c|}{ Kesejahteraan Fungsional (Functional Wellbeing) } \\
\hline $\begin{array}{l}\text { Susah makan makanan yang kamu } \\
\text { inginkan }\end{array}$ & $57(81,4)$ & $3(4,3)$ & $9(12,9)$ & $1(1,4)$ & $0(0)$ \\
\hline Susah tidur & $59(84,3)$ & $10(14,3)$ & $1(1,4)$ & $0(0)$ & $0(0)$ \\
\hline \multicolumn{6}{|c|}{ Kesejahteraan Sosial-Emosional (Socio-emotional Wellbeing) } \\
\hline Merasa khawatir atau gelisah & $45(64,3)$ & $7(10)$ & $13(18,6)$ & $4(5,7)$ & $1(1,4)$ \\
\hline Merasa bahwa kamu terlihat berbeda & $51(72,9)$ & $4(5,7)$ & $13(18,6$ & $2(2,9$ & $0(0)$ \\
\hline $\begin{array}{l}\text { Merasa khawatir dengan apa yang orang } \\
\text { lain pikirkan }\end{array}$ & $55(78,6)$ & $3(4,3)$ & $9(12,9)$ & $3(4,3)$ & $0(0)$ \\
\hline Diejek atau dikatain oleh anak-anak lain & $61(87,1)$ & $7(10)$ & $1(1,4)$ & $1(1,4)$ & $0(0)$ \\
\hline Sedih & $57(81,4)$ & $5(7,1)$ & $5(7,1)$ & $3(4,3)$ & $0(0)$ \\
\hline Susah konsentrasi di sekolah & $61(87,1)$ & $6(8,6)$ & $3(4,3)$ & $0(0)$ & $0(0)$ \\
\hline Percaya diri & $3(4,3)$ & $10(14,3)$ & $18(25,7)$ & $28(40)$ & $11(15,7)$ \\
\hline
\end{tabular}

$\left.{ }^{*}\right)$ Keterangan tabel: $\mathrm{n}$ jumlah responden; \% persentase

**) Setiap pertanyaan diawali dengan kalimat "dalam tiga bulan terakhir, seberapa sering kamu...?" dan diakhiri dengan "...,,karena gigi, mulut atau wajahmu" (untuk domain kesejahteraan fungsional dan sosio-emosional)

$\left.{ }^{* * *}\right) \mathrm{TP}=$ tidak pernah, $\mathrm{SJ}=$ =sangat jarang, $\mathrm{KK}=$ Kadang-kadang, LS=lumayan sering, HSS=hampir setiap saat

Tabel 3. Korelasi antar variabel karies gigi dan kualitas hidup terkait kesehatan rongga mulut untuk tiap domain dan skor total

\begin{tabular}{cccccc}
\hline & $\mathbf{n}$ & $\begin{array}{c}\text { Oral } \\
\text { Health }\end{array}$ & $\begin{array}{c}\text { Functional } \\
\text { Wellbeing }\end{array}$ & $\begin{array}{c}\text { Socio-emotional } \\
\text { Wellbeing }\end{array}$ & $\begin{array}{c}\text { Skor total } \\
\text { OHRQoL }\end{array}$ \\
\hline Karies & 70 & $\mathrm{p}=0,694$ & $\mathrm{p}=0,833$ & $\mathrm{p}=0,536$ & $\mathrm{p}=0,611$ \\
\hline
\end{tabular}

$\left.{ }^{*}\right)$ signifikan bila $\mathrm{p}<0,05$

$\left.{ }^{* *}\right) \mathrm{n}=$ jumlah responden; OHRQoL=Oral health related quality of life (kualitas hidup terkait kesehatan rongga mulut)

Penelitian ini menunjukkan bahwa mayoritas responden tidak pernah mengalami gangguan kesehatan rongga mulut, kesejahteraan fungsional dan kesejahteraan sosial-emosional akibat kondisi oral yang dimilikinya. Hal ini ditunjukkan dengan jawaban mayoritas responden untuk setiap aitem pertanyaan pada setiap domain kuesioner COHIP-SF 19 adalah "tidak pernah" (Tabel 2.) Hal ini sejalan dengan hasil penelitian Tagelsir 
dkk. ${ }^{10}$ yang menyebutkan bahwa pengalaman karies tidak memiliki hubungan dengan kualitas hidup terkait kesehatan rongga mulut anak tunanetra.

Keterbatasan visual yang dimiliki anak tunanetra mengakibatkan penurunan perhatian dan kesadaran mereka akan penampilan 22,23. Hal ini berdampak pada penilaian kesehatan gigi dan mulut. Anak tunanetra tidak mampu menyadari dan mendeteksi tanda-tanda awal penyakit rongga mulut seperti karies sehingga upaya pencegahan dan perawatan terhadap kondisi tersebut mengalami hambatan 24.

Penggunaan indeks DMFT/dmft dalam penelitian ini dapat menyebabkan tidak ditemukannya hubungan antara karies dan kualitas hidup terkait kesehatan rongga mulut. Indeks DMFT/dmft memiliki keterbatasan karena tidak menunjukkan tingkat keparahan atau konsekuensi dari karies yang tidak dirawat yang dapat mempengaruhi kesehatan secara umum dan kualitas hidup ${ }^{25}$. Indeks ini tidak memberi informasi mengenai konsekuensi klinis dari karies yang tidak terawat seperti: keterlibatan pulpa atau abses yang mungkin lebih serius dari karies itu sendiri. Salah satu indeks yang dapat digunakan untuk pengukuran tingkat keparahan karies adalah indeks PUFA. Indeks ini mengukur kondisi oral akibat karies yang tidak dirawat berdasarkan adanya keterlibatan pulpa, ulser, fistula dan abses ${ }^{26}$. Seperti diketahui karies yang parah dan tidak terawat dapat mempengaruhi kualitas hidup seorang anak, mulai dari rasa nyeri, ketidaknyamanan, penampilan yang tidak menyenangkan, gangguan makan dan tidur dan sebagainya ${ }^{26}$.
Individu dengan keterbatasan penglihatan memiliki ekspresi wajah yang terbatas dan respon yang lebih rendah terhadap stimulus ${ }^{27}$. Hal ini dapat menyebabkan respon yang lebih rendah pada indikator kualitas hidup terkait kesehatan rongga mulut yang berhubungan langsung dengan penampilan fisik. Penelitian terdahulu pada 82 anak tunanetra menunjukkan respon yang rendah atau minimnya dampak kesehatan rongga mulut pada kehidupan sehari-hari melalui kuesioner C-OIDP ${ }^{10}$. Tagelsir dkk. ${ }^{10}$ menyebutkan bahwa respon yang rendah ini akibat tidak adanya alat ukur kualitas hidup terkait kesehatan rongga mulut yang dirancang khusus untuk anak disabilitas seperti anak tunanetra.

Keterbatasan penelitian ini adalah rentang usia responden cukup luas meliputi usia anak dan remaja. Rentang usia responden yang cukup luas mampu mempengaruhi hasil penelitian ${ }^{28}$. Usia anak dan remaja memiliki perbedaan karakteristik sehingga menimbulkan perbedaan persepsi individual terhadap penilaian kualitas hidup terkait kesehatan rongga mulut. Kelompok tunanetra di usia remaja tentunya mengalami perubahan lebih signifikan terkait proses pencarian jati diri dan pengakuan oleh lingkungan ${ }^{29}$. Untuk penelitian selanjutnya, diperlukan upaya untuk mengetahui seberapa baik hasil penilaian kualitas hidup dengan menggabungkan persepsi anak dan orang tua 30 terutama untuk anak berkebutuhan khusus yang memperolah pendampingan dari orang tua atau caregiver dalam menjalankan aktivitas sehari-hari. Selain itu, penelitian ini tidak membedakan kapan 
responden mengalami kebutaan. Penyandang tunanetra sejak lahir (bawaan) tidak memiliki pengalaman visual termasuk kondisi gigi dan mulut. Hal ini berbeda dengan individu yang menjadi penyandang tunanetra di usia sekolah atau remaja dan telah memiliki kesan visual sehingga memengaruhi perkembangan dan penilaian individu tersebut terhadap sesuatu hal 29 .

\section{KESIMPULAN}

Karies gigi pada anak tunanetra tidak berhubungan secara signifikan terhadap kualitas hidup terkait kesehatan rongga mulut. Penilaian kualitas hidup terkait kesehatan rongga mulut pada anak tunanetra perlu mempertimbangkan karakteristik anak tunanetra. Keterlibatan orang tua, caregiver atau guru sangat penting untuk memperoleh perspektif kualitas hidup terkait kesehatan rongga mulut pada anak tunanetra yang lebih komprehensif.

\section{UCAPAN TERIMAKASIH}

Penelitian ini terselenggara berkat dukungan moril dan finansial dari Fakultas Kedokteran, Universitas Jenderal Soedirman, selaku unit kerja peneliti.

\section{DAFTAR PUSTAKA}

1. Priyadarshini Pallavi, K Pushpanjali, Sagarkar Anitha et al. Assessment of oral health status among visually impaired children. J Dent Oro-facial Res. 2015;11(1):3-6.

2. Pascolini D, Mariotti SP. Global estimates of visual impairment: $2010 . \mathrm{Br}$ J Ophthalmol. 2012;96(5):614-8.

3. Prashanth ST, Bhatnagar S, Das UM, Gopu H. Oral health knowledge, practice, oral hygiene status, and dental caries prevalence among visually impaired children in Bangalore. J Indian Soc Pedod Prev Dent. 2011;29(2):1025.

4. Parkar S, Patel N, Patel N, Zinzuwadia $\mathrm{H}$. Dental health status of visually impaired individuals attending special school for blind in Ahmedabad city, India. Indian J Oral Sci. 2014;5(2):73.

5. Shewale A, Gattani D, Dhengar Y Lecturer S, Gudadhe B, Meshram S. Oral health status of visually disabled individuals attending blind schools in Nagpur city. Int J Appl Res. 2017;3(6):224-6.

6. Debnadh A, Srivastava BK, Shetty $P$, Eshwar S. New vision for improving the oral health education of visually impaired children- A non randomized control trial. J Clin Diagnostic Res. 2017;

7. Akhter R, Hassan NMM, Martin EF, Muhit M, Smithers-sheedy $\mathrm{H}$, Badawi N, et al. Caries experience and oral healthrelated quality of life (OHRQoL) of children and adolescents with cerebral palsy in a low-resource setting. BMC Oral Health. 2019;19(1):2-7.

8. Papaioannou W, Oulis C. Oral healthrelated quality of life of Greek adults: A cross-sectional study. ... J Jent. 2011;2011.

9. Oliveira O, Ribeiro C, Simões C, Pereira $P$. Quality of life of children and adolescents with visual impairment. $\mathrm{Br} \mathrm{J}$ Vis Impair. 2018;36(1):42-56.

10. Tagelsir A, Khogli AE, Nurelhuda NM. Oral health of visually impaired schoolchildren in Khartoum State, Sudan. BMC Oral Health. 2013;13(1):1.

11. Singh A, Dhawan P, Gaurav V, Rastogi $P$, Singh S. Assessment of oral healthrelated quality of life in 9-15 year old children with visual impairment in Uttarakhand, India. Dent Res J (Isfahan). 2017;14(1):43-9.

12. Broder $\mathrm{HL}$, Wilson-Genderson $M$, Sischo L. Reliability and validity testing for the Child Oral Health Impact ProfileReduced (COHIP-SF 19). J Public Heal Dent. 2012;72(4):302-12.

13. Genderson MW, Sischo L, Markowitz K, Fine D, Broder HL. An overview of children's oral health-related quality of life assessment: From scale 
development to measuring outcomes. Caries Res. 2013;47(SUPPL. 1):13-21.

14. Li C, Xia B, Wang Y, Guan X, Yuan J, $\mathrm{Ge}$ L. Translation and psychometric properties of the Chinese (Mandarin) version of the Child Oral Health Impact Profile-Short Form 19 (COHIP-SF 19) for school-age children. Health Qual Life Outcomes. 2014;12(1):1-8.

15. WHO. Oral Health Surveys: Basic Method 5th, World Health Organization. 2013. 42-43 p.

16. Liu HY, Hu WC, Tang RC, Chen CC, Tsai CC, Huang ST. The impact of dietary and tooth-brushing habits to dental caries of special school children with disability. Res Dev Disabil. 2010;

17. Karamoy Y, Darwita R R M, D A. Menilai Kualitas hidup yang Berhubungan Dengan Kesehatan Mulut Anak Berusia 12 tahun: Validitas Cohip-Sfversi Indonesia. 1394;6(2).

18. Alghamdi $\mathrm{N}$, Alshehri $\mathrm{M}$, Abdellatif $\mathrm{H}$, Assery M, Al Saffan A. Oral health findings, needs and demands of visually impaired children in Saudi Arabia. J Dent Heal Oral Disord Ther. 2018;9(3).

19. Amrollahi N, Amini A, Jafarzadeh M. Parental Awareness about Oral Health Preventive Care and its Relation to DMFT Index in Visually Impaired Children. J Dent. 2020;21(2):106-10.

20. Vabitha Shetty/ Amitha M Hegde / Srikala Bhandary / Kavita Rai. Oral Health Status of the Visually Impaired Children. J Clin Pediatr Dent . 2010;34(3):213-6.

21. Putri $M$, Sirait $T$. penyikatan gigi dengan Pengaruh pendidikan menggunakan model rahang dengan metode pendampingan terhadap tingkat kebersihan gigi dan mulut siswa-siswi SLB-A Bandung. MKB. 2014;46(3):13442.

22. Reddy KVKK, Sharma A. Prevalence of oral health status in visually impaired children. J Indian Soc Pedod Prev Dent. 2011;29(1):25-7.

23. Al-Sarheed M, Bedi R, Hunt NP. The views and attitudes of parents of children with a sensory impairment towards orthodontic care. Eur J Orthod. 2004;26(1):87-91.

24. Meghana Reddy J, Ganapathy DM. Oral hygiene status among visually handicapped. Drug Invent Today. 2019;11(7):1559-63.

25. Ramazani N, Rezaei S. Evaluation of the prevalence of clinical consequences of untreated dental caries using PUFA/pufa index in a group of Iranian children. Iran J Pediatr. 2017;27(1):1-6.

26. Leal SC, Bronkhorst $E M$, Fan $M$, Frencken JE. Untreated cavitated dentine lesions: Impact on children's quality of life. Caries Res. 2012;46(2):102-6.

27. Bolat N, Dongangun B, Yavuz M, Demir $T$, Kayaalp L. Depression and anxiety levels and self-concept characteristics of adolescents with congenital complete visual impairement. Turkish Psikiyatr Dergisi,. 2011;22(2):77-82.

28. Augestad LB. Self-concept and selfesteem among children and young adults with visual impairment: A systematic review. Cogent Psychol. 2017;4(1).

29. Gultom STN, Budisetyani IGAPW. Penerimaan diri difabel (different abilities people): studi tentang remaja tunanetra perolehan. J Psikol Udayana. 2018;5(02):278-86.

30. Sheldrick RC, Neger EN, Shipman D, Perrin EC. Quality of life of adolescents with autism spectrum disorders: Concordance among adolescents' selfreports, parents' reports, and parents' proxy reports. Qual Life Res. 2012;21(1):53-7. 